EPRA International Journal of Economic and Business Review-Peer Reviewed Journal

Volume - 9, Issue -3, March 2021 | e-ISSN: 2347 - 9671| p- ISSN: 2349 - 0187

\title{
ROLE OF TRAINING IN IMPROVING EMPLOYEE'S PERFORMANCE
}

\begin{tabular}{|c|c|}
\hline Atul Kumar & $\begin{array}{c}{ }^{1} \text { Assistant Professor (Guest Faculty), } \\
\text { Department of Commerce, Jananayak } \\
\text { Chandrashekhar University }\end{array}$
\end{tabular}

\section{ABSTRACT}

Article DOI URL: https://doi.org/10.36713/epra6553

Training is important for organisations. It helps in completion of work more efficiently. Training incurs some cost but ultimately it reduces the total cost by reducing material wastages and increases effectiveness of employees so they can do their job in most efficient way. This study gives understanding of how training is important in improving employee's performance. The primary purpose of training is to impart the basic skills in the employee that is required to fulfil his duty.

KEYWORDS: Training, Methods of Training, on the job Training, off the job Training, Employee Performance.

\section{INTRODUCTION}

Training is the way toward expanding the information, and abilities for doing a specific work. It is a coordinated method by which individuals master information and expertise for a positive reason. The motivation behind Training is fundamentally to overcome any issues between work necessities and present skill of a worker. Training is pointed toward improving the conduct and execution of an individual and furthermore it is an endless or consistent cycle.

Today, Indian organisations have understood the significance of Training as an instrument to accomplish their essential objectives. It isn't seen by the organisation as a more drawn out, yet as an speculation on one of its most unique resources, to be specific, workers. Numerous organisations consider Training as an essential worker maintenance instrument. It assists the organisation with making a more brilliant power equipped for meeting any circumstance and difficulties. The primary object of each organisation is to improve its presentation, yet it can never be conceivable without the proficient exhibition of workers. For the organisation, Training prompts improve productivity while developing more uplifting perspectives toward benefit direction. For the people, Training advancement and improve work information while likewise helping in relating to the objectives of the organisation. Training also, advancement is characterized as the arranged learning encounters that instruct representatives step by step instructions to perform current and future positions. At its center is the improvement in the execution of people taking part in Training exercises.

\section{OBJECTIVE}

1. To know what is training and its impact on the employee performance in the organization.

2. To understand the importance of Training

3. To understand the benefits of Employee Training.

4. To know the various methods of Training. 


\section{TRAINING}

Training constitutes a basic concept in human resource development. it's concerned with developing a selected skill to a desired standard by instruction and practice. Training may be a highly great tool which will bring an employee into a footing where they'll do their job correctly, effectively, and conscientiously. Training is that the act of accelerating the knowledge and skill of an employee for doing a selected job.

\section{IMPACT OF TRAINING ON EMPLOYEE PERFORMANCE}

Training helps in sharpen skills of personnel, it makes them gain confidence, perfection and ability to complete a task. Training increases a personnel efficiency by clearing them how to perform the work in the most efficient manner. Under training employees learn how to do a certain kind of job or we can say that how to perform a job in most effective manner so it reduces the chances of loss whether material or machinery and eliminates the chances of industrial accidents. Training is a costly strategy but in long run when we compare the cost and the benefits associated with training it is beneficial for organisation because it reduces the overall cost by reducing the chances of wastages.

\section{IMPORTANCE OF TRAINING}

Training is important for authoritative turn of events and achievement. It is productive to the two managers and workers of an organisation. A worker will turn out to be more proficient and profitable on the off chance that he is prepared well.

Training is given on four fundamental grounds:

1. New competitors who join an organisation are given Training. This preparation acquaint them with the authoritative mission, vision, rules and guidelines and the working conditions.

2. The current representatives are prepared to invigorate and improve their insight.

3. On the off chance that any updates and revisions happen in innovation, Training is surrendered to adapt to those changes. For example, buying another gear, changes in method of creation, PC implantment. The representatives are prepared about utilization of new supplies and work techniques.

4. At the point when advancement and profession development gets significant. Training is given with the goal that representatives are set up to share the duties of the greater level work.

\section{BENEFITS OF EMPLOYEE TRAINING}

Economy in Operations: Trained persons will actually want to improve and practical utilization of materials and equipment's. Wastage will be low. In expansion, the pace of mishaps also, harm to machinery will be kept to the base by the well trained representatives. These will prompt less cost of creation per unit.

More noteworthy Productivity: A very much prepared representative generally shows more prominent profitability and better calibre of workyield than an undeveloped representative. Training builds the abilities of the representatives in the exhibition of a specific work. An increment in the abilities typically assists with expanding both amount and nature of yield.

Less Supervisions: If the workers are given legitimate Training, the obligation of oversight is reduced. Training doesn't kill the requirement for oversight; however it decreases the requirement for point by point and consistent management.

Deliberate Imparting of Skills: A precise Training program assists with decreasing the learning time to arrive at the satisfactory degree of execution. The representatives need not learn by experimentation or by noticing others and sit around idly if the proper Training program exists in the organisation.

Formation of Inventory of Skills: When absolutely new abilities are needed by an organisation, it needs to confront extraordinary challenges in work. Training can be utilized in spotting out promising men and in eliminating surrenders in the choice interaction. It is better to choose and prepare workers from inside the organisation as opposed to look for the talented workers from outside sources.

Higher Morale: The resolve of representatives is increment on the off chance that they are given legitimate Training. A great Training project will shape representatives' mentality to accomplish support for hierarchical exercises and to get more prominent collaboration and dependability. With the assistance of Training, disappointment, objections, non-appearance and turnover can be diminished among the representatives.

\section{TRAINING METHODS}

On the job Training: On the job Training techniques are those which are given to the representatives inside the ordinary working of a concern. It is a straightforward and financially cheap training strategy. The in proficient also as semicapable representatives can be trained by utilizing such training technique. The representatives are prepared in real working situation. The proverb of such Training is "learning by doing." Instances of such on the job Training techniques are work turn, training, brief advancements, and so on

Off the job training: Off the job training strategies are those wherein Training is given away from the real working condition. It is by and large utilized if there should arise an occurrence of new representatives. Occasions of off the job training 
techniques are workshops, classes, meetings, and so on. Such technique is exorbitant and is powerful if and just if huge number of workers must be prepared inside a brief timeframe period. Off the job training is likewise called as vestibule training i.e., the representatives are prepared in a different region (might be a lobby, entrance, gathering area, etc. known as a vestibule) where the real working conditions are copied.

\section{CONCLUSION}

The present study examined the influence of training on employee's performance. It further shows that organizational performance is significantly determined by training imparted to the employees or in other words training is a prerequisite of performance. Performance of a organisation relies on the worker commitment which successively depends on the HR policy of training strategy. The study of relationship of the employees' training with performance is vital for today's managers because new business trends demands more efficiency, accuracy and effectiveness in less time and cost and this could be achieved only through design, development and deployment of effective training programs to the workers. By introducing more training programs within the organization employees become interested to induce more knowledge about their jobs which eventually helps them in getting promotions among their peer groups. Since training has significant influence on employee's work commitment and performance, it's important to strengthen and apply training as a part of organizational agendas in achieving organizational goals.

\section{REFERENCES}

1. Baruch, Y. (2006), "Career development in organizations and beyond: balancing traditional and contemporary viewpoints", Human Resource Management Review,

2. Evans, P., Pucik V. \& Barsoux J-L 2002. The Global Challenge: Framework for International Human Resource Management. Boston: McGrwHill.

3. Ahuja, K. 2006. Personnel management. 3rd Ed. New Delhi. India. Kalyani publishers,

4. Zahid Hussain bhat(2013), Impact of Training on Employee Performance: A Study of Retail Banking Sector in India

5. Afshan Sultana, Sobia Irum, Kamran Ahmed, Nasir Mehmood (2012), impact of training on employee performance: a study of telecommunication sector in Pakistan, interdisciplinary journal of contemporary research in business 